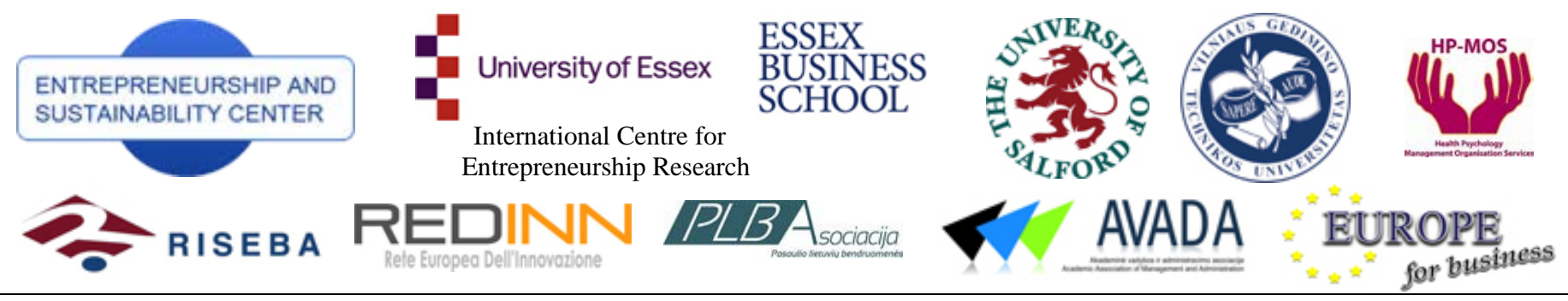

ENTREPRENEURSHIP AND SUSTAINABILITY ISSUES

ISSN 2345-0282 (online) http://jssidoi.org/jesi/

\title{
DEMAND RESPONSE IN BLOCKS OF BUILDINGS: OPPORTUNITIES AND REQUIREMENTS ${ }^{1}$
}

\author{
Tracey Crosbie ${ }^{1}$, Michael Short ${ }^{2}$, Muneeb Dawood ${ }^{3}$, Richard Charlesworth ${ }^{4}$ \\ 1,2,3 School of Science and Engineering \\ Teesside University, Middlesbrough, UK \\ ${ }^{4}$ Siemens plc, Energy Management Division \\ RC-GB EM DG PTI \\ Princess Road, Manchester, UK
}

E-mails: ${ }^{1}$ T.Crosbie@tees.ac.uk; ${ }^{2}$ M.Short@tees.ac.uk; ${ }^{3}$ M.Dawood@tees.ac.uk; ${ }^{4}$ Richard.Charlesworth@siemens.com.

Received 12 October 2016; accepted 10 December 2016

\begin{abstract}
Increased Demand Response (DR) is essential to fully exploit European power systems, which in turn is an absolute prerequisite for meeting European targets related to energy efficiency and climate change. Essentially DR involves consumers reducing or shifting their electricity usage during periods of peak electricity demand in response to time-based tariffs or other forms of financial incentives. The opportunities for realising demand response vary across Europe as they are dependent on the particular regulatory, market and technical contexts in different European counties. Nevertheless successful DR programs are becoming increasingly common for large industrial customers. However DR programs aimed at small and medium scale customers have mostly failed to meet their expected potential. Blocks of buildings offer more flexibility in the timing of energy use, local energy generation and energy storage than single buildings and as such researchers and the energy industry are beginning to consider how blocks of buildings can operate collectively within energy networks to enhance the effectiveness of DR programs. This paper identifies the opportunities and technical, market and regulatory requirements for
\end{abstract}

\footnotetext{
${ }^{1}$ The work presented was carried out as part of the DR BOB project (01/03/16 - 28/02/19) which is co-funded by the EU's Horizon 2020 framework programme for research and innovation under grant agreement No 696114. The authors wish to acknowledge the European Commission for their support, the efforts of the project partners, and the contributions of all those involved in $D R-B O B$.
}

The article reflects the views only of the authors, and the Commission cannot be held responsible for any use which may be made of the information contained therein. The information in this document is provided as is and no guarantee or warranty is given that the information is fit for any particular purpose. The user thereof uses the information at its sole risk and liability 
realising DR services in blocks of buildings in the European context. The work presented is part of an ongoing European Horizon 2020 project entitled Demand Response in Blocks of Buildings.

Keywords: Demand Response (DR), block of buildings, electricity systems, Electric Utilities, Energy networks

Reference to this paper should be made as follows: Crosbie, T., Short, M., Dawood, M., Charlesworth, R., 2016. Demand Response in Blocks of Buildings: Opportunities and Requirements, Entrepreneurship and Sustainability Issues 4(3): 271-

281. http://dx.doi.org/10.9770/jesi.2017.4.3S(3)

JEL Classifications: P18 L94, L90, L98

Additional disciplines: environmental engineering; electricity electronic engineering; law

\section{Introduction}

The European 2030 climate and energy framework adopted in 2014 sets three key binding targets for the year 2030: At least 40\% cuts in greenhouse gas emissions (from 1990 levels); at least a 27\% share for renewable energy; and at least a 27\% improvement in energy efficiency (European Commission 2016a). Increased Demand Response (DR) is an absolute prerequisite for meeting these European energy efficiency and climate change targets. Essentially DR involves consumers reducing or shifting their electricity usage during periods of peak electricity demand in response to time-based tariffs or other forms of financial incentives. The opportunities for realising demand response vary across Europe as they are dependent on the particular regulatory, market and technical contexts in different European counties. Nevertheless successful DR programs are becoming increasingly common for large industrial customers. However DR programs aimed at small and medium scale customers have mostly failed to meet their expected potential. Blocks of buildings offer more flexibility in the timing of energy use, local energy generation and energy storage than single buildings and as such researchers and the energy industry are beginning to consider how blocks of buildings can operate collectively within energy networks to enhance the effectiveness of DR programs (Ala-Juusela et al 2016). This is because blocks of buildings offer more flexibility in the timing of energy use, local energy generation and energy storage than single buildings (Crosbie et al 2016).

The potential value of DR in blocks of buildings depends on the telemetry and control technologies embedded in the building management systems currently deployed at any given site and the potential revenue sources: both of which vary according to specific local and national conditions (Thomas et al 2009, Crosbie et al 2006). In this context, to encourage the growth of DR services' and reap the potential benefits of DR, it is necessary for current research to demonstrate the economic and environmental benefits of DR for the different key actors required to bring DR services in blocks of buildings to market. This is the aim of a current EU funded project called "Demand Response in Blocks of Buildings" (DR BOB) which is co-funded by the EU's Horizon 2020 framework programme for research and innovation. The research presented in this paper is based on the work conducted in the initial stages of the DR BOB project to identify the opportunities and technical, market and regulatory requirements for realising DR services in blocks of buildings in the European context.

Following this introduction, to set the context, section two of this paper outlines the drivers of demand response in blocks of buildings in Europe. In section three of the paper different types of DR programs are defined. Finally section four analyses the potential of each of the DR programs to be deployed in blocks of buildings pointing to the regulatory and market conditions required.

\section{The Drivers of Demand Response in the EU}

The three key binding targets for the year 2030 adopted by the EU in 2014 build on the 2020 climate and energy package which set targets of a $20 \%$ reduction of greenhouse gas emissions, raising the share of EU energy 
consumption produced from renewable resources to $20 \%$ and a $20 \%$ improvement in energy efficiency compared to 1990 levels (European Commission, 2015). As illustrated in Figure 1 energy consumption in the built environment (households and services sector) forms a major portion (40.3\%) of the total energy consumption in EU member states (European Commission, 2014). Thus, energy use in non-industrial buildings offers the potential to make a significant contribution to achieving Europe's targets for climate change and has a very significant impact of peak energy demand. As such it provides a huge largely untapped potential for demand response, offering an avenue for energy aggregators DSOs and TSOs to further manage energy demand.

In efficient energy markets during the hours of peak energy demand energy prices are at their maximum. In relation to electricity, this is because when national electricity demand is low, supply comes from relatively inexpensive base load generation and when demand is high and base load generation is exhausted, supply comes from relatively expensive peaking generators (Crosbie et al 2015). This creates rapidly fluctuating energy costs throughout the day in wholesale electricity markets that peak at times of peak load/ demand (see figure 2). This impacts on the ability of European Industries to compete globally (Capgemini, 2008). Large peaks in energy demand also creates problems with grid reliability, stability and efficiency (Crosbie et al 2015).

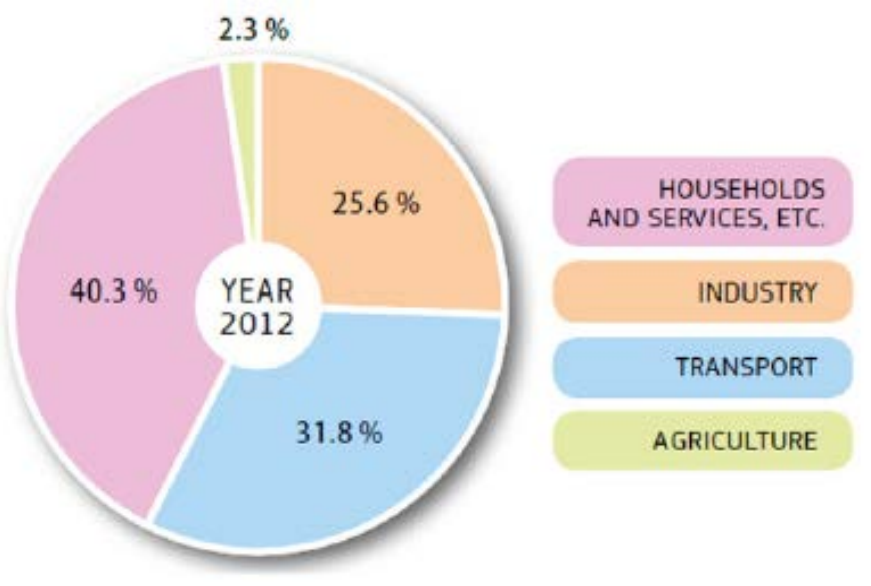

Fig. 1: Breakdown of energy consumption by sector in EU-28 in 2014 (Source European Commission, 2014)

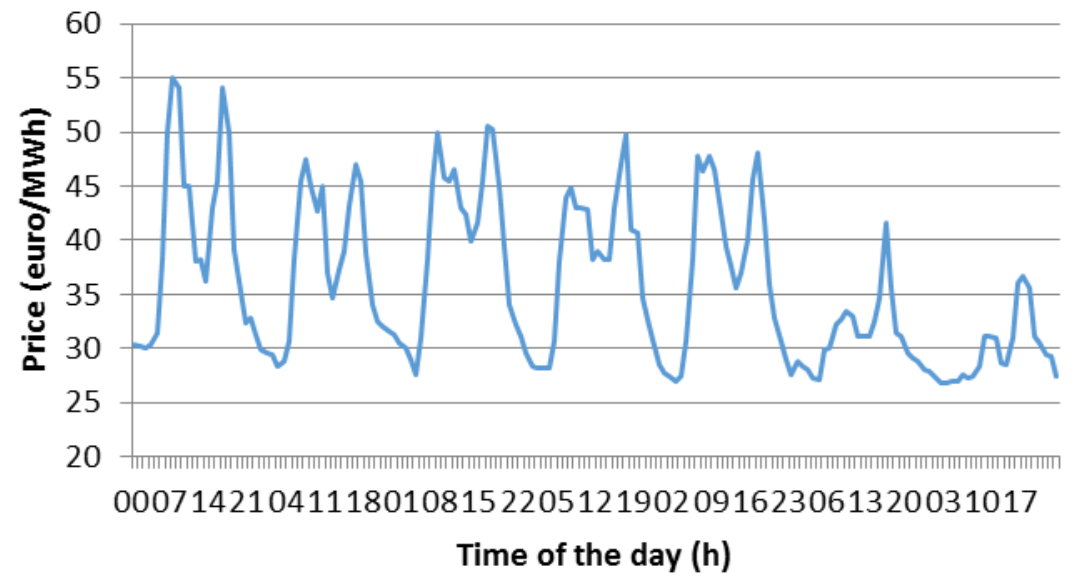

Fig 2.Example of the fluctuation in EU energy markets: Nord Pool Spot prices during an average week (Monday to Sunday) in Finland in February (Source Crosbie et al 2015) 
The growing share of intermittent distributed renewable energy generation in Europe (see Fig 3) is exacerbating the problems created by peak demand in terms of gird security and stability and energy costs. The strong EU policies backing the introduction of renewable energy generation has encouraged this growth in distributed renewable energy which stood at 16 \% in 2015. In 201525 EU countries were meeting their 2013/2014 interim renewable energy targets arising out of the 2020 climate and energy package. This means that the EU has three times more renewable power per capita in Europe than anywhere in the rest of the world. Renewable energy sources are also likely to continue to grow significantly in the near future with the 2030 climate and energy framework set to encourage an increase in the share of renewable to at least $27 \%$ by 2030.

To invest in more capacity is becoming an increasingly expensive option to the challenges created by growing peak energy demand and renewable energy sources, both for utilities and consumers, requiring heavy expenditure on power generation, transmission and distribution capabilities (Capgemini, 2008,Crosbie et all 2015). For example, it is estimated that European electricity networks (EDNs) will require six hundred billion Euros of investments by 2020, with two thirds of these investments required in Distribution networks (Eurelectric 2013). By 2035 the distribution share of the overall network investment is estimated to grow to almost 75 percent and to 80 percent by 2050 (Eurelectric 2013). When thinking about these figures it becomes clear that the prospect that DR solutions to reduce peaks in energy demand is significant. Thus, in recent times, the emphasis is on developing novel solutions which can align the energy demand to the energy supply in real-time (Patteeuwa et al, 2015; Bergaentzlé, 2014). With distributed renewable energy generation and real-time pricing and demand response, the end user can actively participate in energy markets.

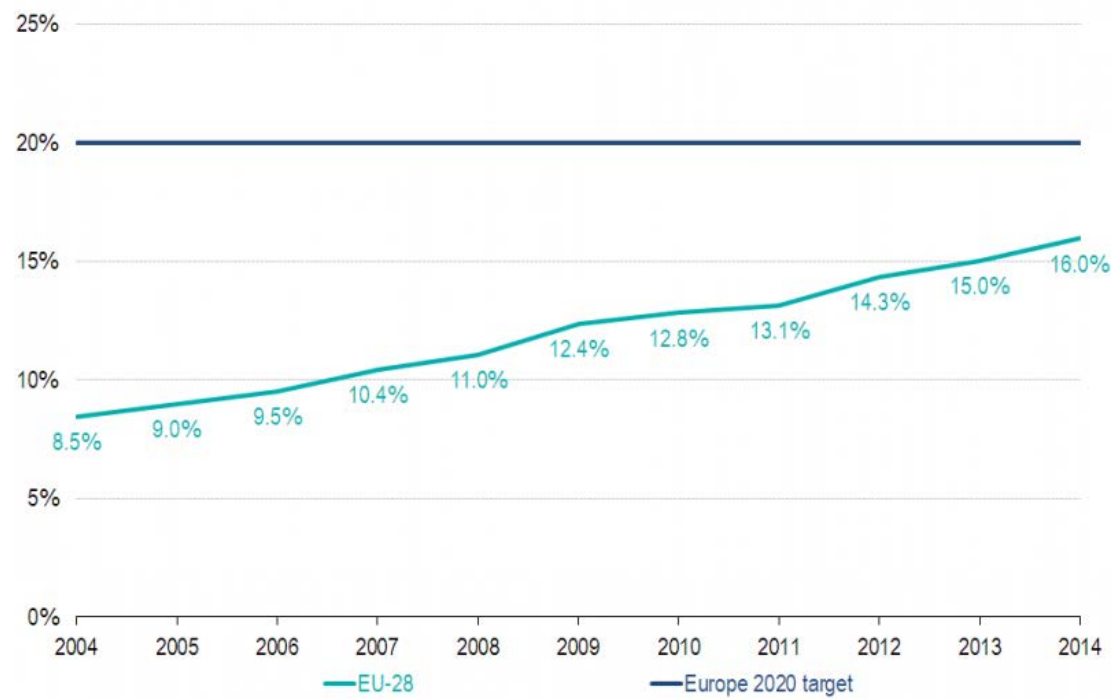

Fig. 3: Share of energy from renewable sources in gross final consumption of energy, EU-28, 2004-2014 (source Eurostat).

Given that more than $40 \%$ of the energy demand from buildings is in the service and domestic sector it would seem that the potential of DR in blocks of buildings is significant and the increasing penetration of DER and climate change targets are significant drivers of demand response. However to fully realise the potential for DR in blocks of buildings, it will be necessary to identify which types of DR response programs are applicable to blocks of buildings in different technical market and regulatory contexts as discussed in the following sections.

\section{Demand Response program architypes}


The International Journal

ENTREPRENEURSHIP AND SUSTAINABILITY ISSUES

ISSN 2345-0282 (online) http://jssidoi.org/jesi/

2017 Volume 4 Number 3 (March)

Although DR programmes are to a certain extent unique - having to fit specific geographic and regulatory requirements - common elements and characteristics can be identified. Earlier research identified seven main DR program types (OpenADR Alliance 2016) and this work forms the basis of the types of DR programs discussed here. However those DR programs involving cost and pricing signals for typical DR programs involving variable tariffs - such as traditional Critical Peak Pricing (CPP), Real-Time Pricing (RTP), Time of Use Pricing (TOUP), Two-Tier Pricing (2TP) and various combinations thereof, can be combined. Therefore to simplify the analysis that follows, DR programs involving these pricing signals have been merged into a single 'Generic Variable Tariff' DR program.

Generic Variable Tariff (GVT) DR program: GVT DR programs provide variable pricing structures for electricity which are designed to reduce consumption during periods of high wholesale market price or during known periods of system contingency, and encourage consumption in times of low wholesale market price. In a GVT program, hourly or sub-hourly prices for electricity consumption (possibly having several tiered levels) will be advertised to DR participants by the program sponsor at least one hour in advance, typically one day in advance and in some cases even months in advance. Although prices are variable and reflect market conditions, maximum prices may be negotiated in advance. Typically they are linked to day-ahead market conditions and seasonal market changes. Such DR programs are especially useful for planning and scheduling controllable resources such as smart appliances and the charging times of electric vehicles. There are no minimum load restrictions and the targeted participants may be residential, commercial or industrial.

Capacity Bidding DR Program (CPB): A DR program which allows a load resource and its owner to identify how much load it is willing to curtail for a specific price to the DR program sponsor requiring the demand reduction. Although CPB contracts may be negotiated by the resource owner and the sponsor well in advance, real-time negotiation may also be performed e.g. based upon balancing (real-time) market conditions to help cover unplanned contingencies such as loss of expected renewable availability due to inaccurate weather forecasts. Notice periods for activating negotiated CBP contracts are typically one hour minimum and are mostly one dayahead. Such DR programs are especially useful for deferring planned operation of large/medium sized industrial loads, where enforced loss or change of production is recouped through pre-commitment contracts and subsequent activation payments. There are minimum load restrictions (typically $100 \mathrm{~kW}$ ) and the targeted participants may be load aggregators, commercial or industrial.

Direct Load Control (DLC) DR Program: A DR activity in which the program sponsor remotely controls a participant's electrical equipment on short notice (normally several hours). Typically this would involve temporarily reducing temperature, humidity or air pressure set points in home and building HVAC equipment to achieve a short-term reduction in electricity demand. Once the DR event has passed, conditions are automatically returned to nominal levels. Financial incentives are paid for enrolling in the DR program and may also include bonuses when DR events occur. It is possible for a participant to opt-out of a given DR event for a financial penalty. There are no minimum load restrictions and the targeted participants may be residential or (small) commercial.

Fast Dispatch / Ancillary Services (FD/AS) DR Program: A DR program which provides incentive payments to participants for fast load reductions (or increases in some cases) during emergency conditions on the grid that require immediate action to prevent loss of transmission lines, distribution equipment and/or generator tripping which can negatively impact the reliability of the wider system. Contracts are negotiated in advance and often activated without prior warning, as load needs to be shed (or increased) at very short notice ( $\approx 2$ seconds for frequency regulation). Such DR programs are especially useful for large/medium sized industrial loads where enforced loss or change of production is recouped through pre-commitment contracts and subsequent activation payments. There are minimum load restrictions (typically $100 \mathrm{~kW}$ ) and the targeted participants may be load aggregators, commercial or industry. This DR program is very similar to the CBP DR program, but timescales for 
real-time response and reliability of load change are much more stringent (and participation incentives much larger).

Distributed Energy Resources (DER) DR Program: These are DR activities which are utilised to smooth integration issues for Distributed Energy Resources (DER) into the wider electricity grid, e.g. to help curtail over or undersupply issues. For most implementations of this DR program, some form of storage and/or a dispatchable 2 DER are required. The DR participant responds to day-ahead pricing signal incentives from the sponsor to either increase or decrease its nominal load at requested times during the day, using batteries, flywheels or other forms of energy storage or by dispatching a DER for a particular time period when it would not normally do so. This allows the DR participant to modify its nominal load profile in accordance with the sponsors' incentives (which are often linked to intermittent availability of renewable energy elsewhere in the grid). There are no minimum load restrictions and the targeted participants may be residential, commercial or industrial.

\section{Potential of DR Programs for Blocks of Buildings}

The different types of DR programmes outlined in the previous section all have potential for DR in blocks of buildings. However some maybe expected to be deployed more easily in a wider variety of situations than others due to significant variations in their technical, market and regulatory requirements.

Table 1 below presents an assessment of the different types of DR programmes for deployment in blocks of buildings based upon an estimation of the level of effort required and technical and regulatory considerations related to the implementation of each DR program. Note that since all DR programs require an existing Advanced Metering Infrastructure (AMI) and DR ICT infrastructure, this is not stated as an explicit technical requirement.

Table 1. Technical, Market and Regulatory Requirements for DR Programs block of buildings potential

\begin{tabular}{|c|c|c|c|c|}
\hline DR Program & $\begin{array}{l}\text { DR Incentive and } \\
\text { Impacts }\end{array}$ & Technical Requirements & $\begin{array}{l}\text { Regulatory and market } \\
\text { requirements }\end{array}$ & $\begin{array}{l}\text { Block of } \\
\text { Buildings } \\
\text { Potential }\end{array}$ \\
\hline $\begin{array}{l}\text { General Variable } \\
\text { Tariff (GVT) }\end{array}$ & $\begin{array}{l}\text { Low to medium } \\
\text { economic benefit to } \\
\text { participant, continual } \\
\text { peak-to-peak reduction }\end{array}$ & $\begin{array}{l}\text { Schedulable / controllable devices or } \\
\text { Electric vehicle (EV) charge points, } \\
\text { Optimizer, Human-machine interface } \\
\text { (HMI), Building management system } \\
\text { (BMS) or Home area network (HAN). }\end{array}$ & Relevant variable tariffs & Very High \\
\hline $\begin{array}{l}\text { Capacity } \\
\text { Bidding DR } \\
\text { Program (CBP) }\end{array}$ & $\begin{array}{l}\text { High economic benefit } \\
\text { to participant, sporadic } \\
\text { peak reduction }\end{array}$ & $\begin{array}{l}\text { Sheddable load of } 100 \mathrm{~kW} \text { or more, } \\
\text { HMI }\end{array}$ & $\begin{array}{l}\text { Relevant CBP DR product } \\
\text { and load aggregators }\end{array}$ & Low \\
\hline $\begin{array}{l}\text { Direct Load } \\
\text { Control (DLC) }\end{array}$ & $\begin{array}{l}\text { Medium economic } \\
\text { benefit to participant, } \\
\text { sporadic peak and } \\
\text { energy usage reduction }\end{array}$ & $\begin{array}{l}\text { HVAC with appropriate control system } \\
\text { or other suitable load, HMI, BMS or } \\
\text { HAN }\end{array}$ & $\begin{array}{l}\text { Relevant DLC product and } \\
\text { load aggregators }\end{array}$ & High \\
\hline $\begin{array}{l}\text { Fast Dispatch / } \\
\text { Ancillary } \\
\text { Services } \\
\text { (FD/AS) }\end{array}$ & $\begin{array}{l}\text { Potentially very high } \\
\text { economic benefit to } \\
\text { participant, sporadic } \\
\text { peak reduction }\end{array}$ & $\begin{array}{l}\text { Fast sheddable load of } 100 \mathrm{~kW} \text { or more, } \\
\text { Plus high-speed and reliable telecontrol } \\
\text { \& telemetry interfaces OR frequency } \\
\text { sensitive / frequency aware loads }\end{array}$ & $\begin{array}{l}\text { Relevant FD/AS products and } \\
\text { load aggregators }\end{array}$ & Very Low \\
\hline $\begin{array}{l}\text { Distributed } \\
\text { Energy } \\
\text { Resources }\end{array}$ & $\begin{array}{l}\text { Medium to high } \\
\text { economic benefit to } \\
\text { participant, continual }\end{array}$ & $\begin{array}{l}\text { Dispatchable DER, Storage, Optimizer, } \\
\text { HMI, BMS or HAN }\end{array}$ & $\begin{array}{l}\text { Relevant variable tariffs } \\
\text { allowing renewable energy } \\
\text { self-consumption and }\end{array}$ & Medium \\
\hline
\end{tabular}

\footnotetext{
${ }^{2}$ Dispatchable renewable energy refers to sources of renewable electricity that can be dispatched at the request of power grid operators or of the plant owner; that is, renewable generating plants that can be turned on or off, or can adjust their power output accordingly to an order.
} 
The most favourable DR programs according to this initial evaluation are GVT, DLC and DER. This is principally because in most (not all) blocks of buildings have some controllable appliances (e.g. washing machines and EV chargers etc.) and HVAC systems for climate control (temperature and humidity). Since market conditions in most EU countries already support simple on-peak and off-peak tariff structures - and many are moving towards RTP pricing structures - the basics for implementing GVT and DLC DR Programs are present, even if manual implementations are required. In addition, in many modern buildings, distributed energy generation is also present (typically in the form of PV panels and/or a CHP plant). Therefore a DER DR program also seems favourable, albeit slightly less so due to the additional need for storage and day-ahead signal from the DR sponsor.

The main reason for less favourable conditions for the CPB and FD/AS DR programs is the need for a controllable resource which is large enough to be activated (at very short notice in the FD/AS case). This is less likely to be available in a block of buildings. However, in many cases it is most likely that hybrid combinations of the DR programs outlined in section 3 can be considered for a particular area. For example, recent works by Zhou et al. (2015) and Patteeuwa et al. (2015) have shown that by aggregation of multiple HVAC systems and the application of co-ordinated controls, it is possible to provide FD/AS-type DR programs to provide demand-side frequency regulation services to support intermittency of renewable generation, e.g. in the presence of fluctuating wind power. The work by Patteeuwa et al. (2015) also considers the use and role of thermal storage units in such applications. These DR approaches are, in essence, hybrid combinations of DLC, FD/AS and DER DR programs which are enabled and supported by appropriate ICT infrastructures and control/optimization systems.

Another possible approach to providing fast ancillary and dispatch services for leveraging demand-side contributions to frequency regulation could also be emerging (Molina-García et al. 2011; Villena et al. 2015). In this decentralised approach, instead of having demands under tele-control by a DR sponsor, loads are equipped with (low-cost) instrumentation which is able to measure frequency directly at the point of supply. They are also equipped with controls which can quickly react to frequency deviations by modulating demand accordingly, without the need for any external signals. If properly implemented, a form of fast-acting demand-side primary droop control can be achieved by participating loads. Follow-up secondary frequency stabilisation using telecontrol signals from the DR sponsor can also be used within such a framework ('traditional' DR). With respect to blocks of buildings, then HVAC systems seem to be the most appropriate for this kind of droop control by manipulating temperature and air-flow set-points to obtain fast, short-term reductions in demand (which are not likely to impact occupant comfort if only present for short time periods). This approach avoids the need for fast and reliable tele-control and telemetry interfaces and infrastructures, but requires the development of an appropriate set of technical standards and legislation. However currently seems to be a minimal market with few financial incentives offered for providing such services within the EU. This is currently a barrier to an approach which appears to be emerging as one of the most technically feasible and potentially effective approaches for DR. Current exceptions are the Frequency Control by Demand Management (FCDM) and Enhanced Frequency Response (EFR) services introduced in 2016 as part of a range of demand-side management initiatives for the UK market (Proffitt 2016). FCDM is a tendered balancing service which requires that a load of $3 \mathrm{MW}$ minimum is shed by participants within 2 seconds of the system frequency falling below a preset threshold, for minimum duration 30 minutes. EFR extends traditional primary frequency controls to the demand side in the manner described above, but the product is still in development and the technical and contractual requirements not yet fixed.

An example of how DR involving the control of local energy production are inhibited in some EU countries is the way in which the price paid to individuals and organisations that generate renewable energy is subsidised. Many EU countries have introduced Feed-in-Tariffs (FITs) that guarantee a price for the renewable electricity produced 


\section{ENTREPRENEURSHIP AND SUST \\ The International Journal
TAINABILITY ISSUES}

ISSN 2345-0282 (online) http://jssidoi.org/jesi/

2017 Volume 4 Number 3 (March)

by distributed energy resources. Two types of tariff schemes are commonly applied: fixed-price FITs (FFITs) which guarantee a fixed price for every unit of produced electricity and premium based FITs (PFITs) which pay a premium on top of the variable market price (Crosbie 2016). "FFITs do not provide any incentive to produce electricity when marginal production costs are high. Also, costs for balancing intermittent electricity production may be significantly lower with PFITs. Therefore, PFITs provide an incentive to match renewable power output better with marginal production costs in the system" (Schmidt, 2013). So, for example, in France while recent changes to regulations make self-consumption possible the currently very generous FFITs make this financially unrewarding.

It would seem that within a block of buildings scenario featuring large enough quantities of schedulable devices and controllable loads - along with DER/storage units (e.g. CHP with batteries / hot water tank) - modern optimization and control techniques such as those described by Ogwumike et al. (2016), Short et al. (2016), Patteeuwa et al. (2015) and Zhou et al. (2015) - including others - allow for potentially large opportunities for DR in blocks of buildings. A key enabling factor, however, will be the selection and deployment of an appropriate AMI/DR ICT framework to assist with coordinated actions between buildings and blocks of buildings, and the selection and deployment of appropriate local controls and optimisers.

In the case of DER DR it must be highlighted that there are three key barriers to consider when thinking about the potential for the deployment of DER DR in blocks of buildings in some EU countries. Firstly renewable energy self-consumption and decentralised storage are not allowed in all EU countries (European Commission 2016b). Secondly complex and burdensome administrative and authorisation procedures still represent an important barrier for the competiveness of small-scale self-consumption projects in blocks of buildings where renewable energy self-consumption and decentralized storage are allowed (European Commission 2016b). Thirdly on-line information platforms and applications are so far used in only a few Member States (e.g. Portugal, Hungary, Italy and Sweden) (European Commission 2016b). Thus while several EU countries have introduced facilitated notification procedures for small renewable energy installations such as roof-top PV installations, additional national action is required (European Commission 2016a).

When considering the potential for DR in blocks of buildings the rise of the independent aggregator within European electricity markets is also crucial. As demand response in blocks of buildings will be difficult to capitalise on in those EU countries whose regulatory frameworks discourage or ban their growth. This is especially in the case of Explicit DR programs in which consumers receive direct payments to change their consumption (or generation) patterns upon request, such as what we have called CPD, DLC and FD/AS. This is because most blocks of buildings do not have the level of generation / demand reduction/ storage capacity to engage in many of the current DR products. Consumers, if they are to be engaged in DR need a clearly defined offer, which is clearly beneficial and simple to use. As such they "require a party with expertise in selling and providing this offer through aggregation. Aggregation service providers (who may or may not be electricity suppliers) are therefore central players in creating vibrant demand-side participation and Explicit Demand Response” (SEDEC 2015).

In 2015 an analysis ${ }^{3}$ of sixteen of the EU's member states found six EU member states have commercially active explicit demand response markets; while a further four states had partial opening of demand response markets and two were found to have no current opening of the market for explicit demand response (SEDEC 2015). However, there are considerable barriers in many countries to be overcome before there is an EU market for a solution to enable explicit demand response in blocks of buildings. One of the key barriers being that in most EU countries consumers cannot choose a separate service provider for providing demand response. "They are

\footnotetext{
3 This analysis graded markets according to the four main criteria: 1) Enabling consumer participation and aggregation 2) Appropriate programme requirements 3) Fair and standardised measurement and verification requirements and 4) Equitable payment and risk structures.
} 
restricted to their supplier, or at least need their supplier's permission before working with a third party aggregator. Often the supplier is in direct competition with the aggregator, or may have other reasons to hamper the uptake of Demand Response, and thus has an incentive to block the aggregator from doing business with the consumer" (SEDEC 2015).

The pilot sites in the DRBOB project are situated in France, Italy, the UK and Romania. Of these the markets in France and the UK have commercially active explicit demand response markets, while in the pilot site countries all except Romina have current variable energy tariffs. The findings presented suggest that in the first instance the demonstrations in the DRBOB project should seek to illustrate the potential of existing capacity bidding (across all sites), variable tariffs (UK, France, Italy) and direct load control programs (UK, France) to underpin demand response in blocks of buildings. However, it is also noted that energy tariffs which offer real incentives for demand response and DLC products are not available in all EU countries and these markets will need further development. For demonstration of decentralised fast ancillary and dispatch services, the UK market seems to be most appropriate with some early DR products currently available and others in latter planning stages.

In summary the UK market, at present, offers the largest scope for DR demonstrations at the block of buildings level due to its recent initiatives on the demand side in general. The outputs of the DR-BOB project will therefore include an assessment of potential socio-technical (Grünewald, et al. 2012) and techno-economic (Crosbie et al 2016) barriers to DR deployment in blocks of buildings, to guide less mature market development using the UK market (and its emerging operational and contractual specifications) as a reference point. Following energy studies informed by the social sciences (Crosbie 2006, Crosbie and Baker 2009, Stephenson et al 2010, Grünewald, et al. 2012) the approach adopted will involve in-depth interviews with stakeholders (including facilities managers, building owners and building occupants) to explore the various perspectives, motivations and vested interests which are at play when seeking to implement demand response in blocks of buildings.

\section{Conclusion}

The different types of DR programmes discussed all have potential for DR in blocks of buildings. However given the different technical market and regulatory contexts in different EU countries some will be deployed with greater ease in some countries than others. To address the uneven development of the technical, market and regulatory requirements for realising DR services in blocks of buildings the DR-BOB project will seek to identify how mechanisms for DR response from more mature markets could be implemented in EU countries with less mature markets for DR (Crosbie at al. 2016). The results will provide feedback to the market participants with recommendations on how that country could adopt new mechanisms and what value there is in doing so for the different actors involved in the value chain required to bring DR in blocks of buildings to market (Crosbie et al 2016).

\section{Acknowledgements}

The work presented was carried out as part of the DR BOB project (01/03/16 - 28/02/19) which is co-funded by the EU's Horizon 2020 framework programme for research and innovation under grant agreement No 696114. The authors wish to acknowledge the European Commission for their support, the efforts of the project partners, and the contributions of all those involved in $D R-B O B$.

The article reflects the views only of the authors, and the Commission cannot be held responsible for any use which may be made of the information contained therein. The information in this document is provided as is and no guarantee or warranty is given that the information is fit for any particular purpose. The user thereof uses the information at its sole risk and liability 


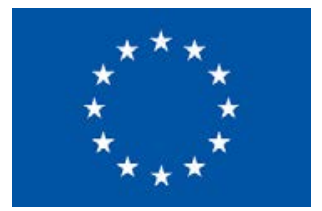

\section{References}

Ala-Juusela, M., Crosbie, T., and Hukkalainen, M., (2016) Defining and Operationalising the Concept of an Energy Positive Neighbourhood" Energy Conversion \& Management. 125:133-140. http://dx.doi.org/10.1016/j.rser.2010.07.067

Bergaentzlé, C., Clastres, C. and Khalfallah, H. (2014) Demand-side management and European environmental and energy goals: An optimal complementary approach. Energy Policy, 67, 858-869. http://dx.doi.org/10.1016/j.enpol.2013.12.008

Capgemini (2008) Demand Response: a decisive breakthrough for Europe. Available at: https://www.capgemini.com/resource-fileaccess/resource/pdf/Demand Response a decisive breakthrough for Europe.pdf

Crosbie, T. (2006) 'Household energy studies: the gap between theory and method', Energy and Environment, 17(5)735-753. http://journals.sagepub.com/doi/abs/10.1260/0958-305X.17.5.735

Crosbie, T. and Baker, K. (2009) Energy Efficiency Interventions: Learning from the inhabitants Building Research \& Information 38 (1): 70 - 79. . http://dx.doi.org/1016/j.enpol.2013.12.008

Crosbie, T., Dawood, M., Short, M., Brassier, P., Dorcome, R., Huovila and A., and Ala-Juusela M., (2015) Generalised business models. Deliverable 2.3 of IDEAS project: $\underline{\text { http://dx.doi.org/10.13140/RG.2.1.1900.2960 }}$

Crosbie, T., Vukovic, V., Short, M., Dawood, N., Charlesworth, R. \& Brodrick, P. (2016) "Future demand response services for blocks of buildings". Proceedings of the 1st AIC Conference on 1st EAI International Conference on Smart Grid Inspired Future Technologies, Liverpool, Great Britain, May, 19-20. http://dx.doi.org/10.1007/978-3-319-47729-9 http://link.springer.com/book/10.1007\%2F978-3-319$\underline{47729-9}$

Eurelectric (2013). Power distribution in Europe: facts and figures. Union of the Electricity Industry -EURELECTRIC aisbl, Belgium. Available at: http://www.eurelectric.org/media/113155/dso_report-web_final-2013-030-0764-01e.pdfhttp://www.eurelectric.org/media/113155/dso_report-web_final-2013-030-0764-01-e.pdf

European Commission (2014) Transport Statistical pocketbook 2014. http://dx.doi.org/10.2832/63317

European Commission (2015) EU climate and energy package. Available at: http://ec.europa.eu/clima/policies/package/index_en.htm

European Commission (2016a) 2030 Climate \& Energy Framework: Available at: http://ec.europa.eu/clima/policies/strategies/2030_en

European Commission (2016b) Best practices on Renewable Energy Self-consumption. Available at:

http://ec.europa.eu/energy/sites/ener/files/documents/1_EN_autre_document_travail_service_part1_v6.pdf

Grünewald, P.H., Cockerill, T., Contestabile, M., and Pearson P.J.G. (2012) The socio-technical transition of distributed electricity storage into future networks - System value and stakeholder views, Special Issue: Past and Prospective Energy Transitions - Insights from History, Energy Policy, November 2012, p.p. 449-457. http://dx.doi.org/10.1016/j.enpol.2012.07.041

Molina-García, A., Bouffard, F. and Kirschen, D.S. (2011) Decentralized Demand-Side Contribution to Primary Frequency Control, IEEE Transaction on Power Systems, Vol. 26, No. 1, pp. 411-419. http://dx.doi.org/10.1109/TPWRS.2010.2048223

Ogwumike, C., Short, M. and Abugchem, F. (2016) Heuristic Optimization of Consumer Electricity Costs using a Generic Cost Model, Energies, ISSN: 1996-1073, Vol. 9, No. 6. http://dx.doi.org/10.3390/en9010006

OpenADR Alliance (2016) OpenADR 2.0 Demand Response Program Implementation Guide (Version 1.0), Document Number: 20140701, April 2016.

Patteeuwa, D., Bruninxa, K., Arteconic, A., Delaruea, E., D’haeseleera, W. and Helsena, H. (2015) Integrated modeling of active demand response with electric heating systems coupled to thermal energy storage systems. Applied Energy, 151, 306-319.

http://dx.doi.org/10.1016/j.apenergy.2015.04.014

Proffitt, E. (2016) Profiting from Demand Side Response. The Major Energy Users' Council in association with National Grid: Technical Publication, U.K., 2016.

Stephenson J, Barton B, Carrington G, Gnoth D, Lawson R, Thorsnes P. (2010) Energy cultures: a framework for understanding energy behaviours. Energy policy. 38 (10):6120-9. http://dx.doi.org/10.1016/j.enpol.2010.05.069 
Smart Energy Demand Coalition SEDC (2015) Mapping demand response in Europe today (2015) Available: http://www.smartenergydemand.eu/wp-content/uploads/2015/09/Mapping-Demand-Response-in-Europe-Today-2015.pdf

Short, M., Crosbie, T., Dawood, M. \& Dawood, N. (2016) Load Forecasting and Dispatch Optimisation for Decentralised Co-generation Plant with Dual Energy Storage. Applied Energy, 186 (3):304-320. http://dx.doi.org/10.1016/j.apenergy.2016.04.052

Thomas, C., Star, A. and Kim, J. (2009) An Assessment of business models for demand response. In: Proceedings of grid-interop forum, Denver, USA.

Villena, J., Vigueras-Rodríguez, A., Gómez-Lázaro, E., J.A. Fuentes-Moreno, Muñoz-Benavente, I. and Molina-García, A. (2015) An Analysis of Decentralized Demand Response as Frequency Control Support under Critical Wind Power Oscillations, Energies, 8: 1288112897. http://dx.doi.org/10.3390/en81112349 http://www.mdpi.com/1996-1073/8/11/12349

Zhou, L., Li, Y., Wang, W., and Hu, X. (2015) Provision of Supplementary Load Frequency Control via Aggregation of Air Conditioning Loads. Energies, 8: 14098-14117. http://dx.doi.org/10.3390/en81212417 http://www.mdpi.com/1996-1073/8/12/12417

\section{Authors}

Dr Tracey CROSBIE is a Senior Research Lecturer in Energy Reduction at Teesside University. She has been researching issues associated with energy consumption in built environment and ways of informing its reduction for more than fifteen years. She is a transdisciplinary academic with degrees in the social and technical sciences. Her main research interests involve the development of sociotechnical approaches to applying ICTs to urban sustainability and the development of business models to exploit those ICTs. She has a wide experience of research within the Utilities industry and managing EU projects and work packages.

ORCID ID: 0000-0002-9355-4816

Dr Michael SHORT is a Reader in Electronics and Control at Teesside University. He is the technical coordinator of the DR_BOB H2020 Innovation project. He is a full member of the Institute of Engineering and Technology (MIET), a member of the Institute of Electrical and Electronic Engineers (IEEE), and sits on the Fault Tolerant and Dependable Systems (FTDS) sub-committee of the IEEE Industrial Electronics society.

ORCID ID 0000-0001-6290-4396

Dr Muneeb DAWOOD is a Research Assistant at Technology Futures Institute, TU. He has a PhD degree in Communication (Electrical) Engineering and an MSc degree in Telecommunications and Computer Networks Engineering. His experience and research interests include modelling and simulation of renewable energy resources, real-time communication protocols for wired and wireless networks, error-resilience techniques for real-time communication, monitoring protocols and communication infrastructure for smart grid and visualization of scientific data.

ORCID ID:0000-0002-1427-4331

Richard CHARLESWORTH is a Solution Architect for Siemens and has over 20 years of experience in IT in a variety of roles from developer to Lead Technical Architect. He has over 15 years proven track record in utilities and metering systems of all sizes. Richard was responsible for key stages technical bid, specification, design and delivery of the Manchester Triangulum project, and otherwise has consulted on Smart Metering, Demand Response and eCar across UK and Europe. He was Lead Author on the Low Carbon London "Report 10 - Opportunities for smart optimization of new heat and transport loads." He is also leads a technical work package in the DR_BOB H2020 project.

ORCID ID: 0000-0001-8182-4383

Copyright (C) 2016 by author(s) and VsI Entrepreneurship and Sustainability Center

This work is licensed under the Creative Commons Attribution International License (CC BY).

http://creativecommons.org/licenses/by/4.0/

cC (i) Open Access 